\title{
Brain immaturity is associated with brain injury before and after neonatal cardiac surgery with high-flow bypass and cerebral oxygenation monitoring
}

\author{
Dean B. Andropoulos, MD, MHCM, ${ }^{\mathrm{a}, \mathrm{b}, \mathrm{f}}$ Jill V. Hunter, MD, ${ }^{\mathrm{c}, \mathrm{h}}$ David P. Nelson, MD, ${ }^{\mathrm{b}, \mathrm{i}}$ \\ Stephen A. Stayer, MD, ${ }^{\mathrm{a}, \mathrm{b}, \mathrm{f}}$ Ann R. Stark, MD ${ }^{\mathrm{b}, \mathrm{j}}$ E. Dean McKenzie, MD, ${ }^{\mathrm{d}, \mathrm{g}}$ Jeffrey S. Heinle, MD, ${ }^{\mathrm{d}, \mathrm{g}}$ \\ Daniel E. Graves, $\mathrm{PhD},{ }^{\mathrm{e}}$ and Charles D. Fraser, Jr, $\mathrm{MD}^{\mathrm{b}, \mathrm{d}, \mathrm{g}}$
}

\begin{abstract}
Background: New intraparenchymal brain injury on magnetic resonance imaging is observed in $36 \%$ to $73 \%$ of neonates after cardiac surgery with cardiopulmonary bypass. Brain immaturity in this population is common. We performed brain magnetic resonance imaging before and after neonatal cardiac surgery, using a high-flow cardiopulmonary bypass protocol, hypothesizing that brain injury on magnetic resonance imaging would be associated with brain immaturity.
\end{abstract}

\begin{abstract}
Methods: Cardiopulmonary bypass protocol included $150 \mathrm{~mL} \cdot \mathrm{kg}^{-1} \cdot \mathrm{min}^{-1}$ flows, $\mathrm{pH}$ stat management, hematocrit $>30 \%$, and high-flow antegrade cerebral perfusion. Regional brain oxygen saturation was monitored, with a treatment protocol for regional brain oxygen saturation $<50 \%$. Brain magnetic resonance imaging, consisting of T1-, T2-, and diffusion-weighted imaging, and magnetic resonance spectroscopy were performed preoperatively, 7 days postoperatively, and at age 3 to 6 months.
\end{abstract}

\begin{abstract}
Results: Twenty-four of 67 patients ( $36 \%$ ) had new postoperative white matter injury, infarction, or hemorrhage, and $16 \%$ had new white matter injury. Associations with preoperative brain injury included low brain maturity score $(P=.002)$. Postoperative white matter injury was associated with single-ventricle diagnosis $(P=.02)$, preoperative white matter injury $(P<.001)$, and low brain maturity score $(P=.05)$. Low brain maturity score was also associated with more severe postoperative brain injury $(P=.01)$. Forty-five patients had a third scan, with a $27 \%$ incidence of new minor lesions, but $58 \%$ of previous lesions had partially or completely resolved.

Conclusions: We observed a significant incidence of both pre- and postoperative magnetic resonance imaging abnormality and an association with brain immaturity. Many lesions resolved in the first 6 months after surgery. Timing of delivery and surgery with bypass could affect the risk of brain injury. (J Thorac Cardiovasc Surg 2010;139:543-56)
\end{abstract}

Despite current survival rates of greater than $90 \%,{ }^{1}$ up to $50 \%$ of children age 5 years or older who had cardiac surgery as newborns or young infants have long-term neurodevelopmental impairment. ${ }^{2}$ These children have problems that are similar to those seen in premature infants, including

\footnotetext{
From the Departments of Anesthesiology, ${ }^{\mathrm{a}}$ Pediatrics, ${ }^{\mathrm{b}}$ Radiology, ${ }^{\mathrm{c}}$ and Surgery, ${ }^{\mathrm{d}}$ Physical Medicine and Rehabilitation, ${ }^{\mathrm{e}}$ Baylor College of Medicine, Division of Pediatric Cardiovascular Anesthesiology, ${ }^{f}$ Congenital Heart Surgery Service, ${ }^{\mathrm{g}}$ Sections of Pediatric Neuroradiology, ${ }^{\mathrm{h}}$ Pediatric Cardiology, ${ }^{\mathrm{i}}$ and Neonatology, ${ }^{\mathrm{j}}$ Texas Children's Hospital, Houston, Tex.

Disclosures: Dr Andropoulos is supported in part by NIH National Institute of Child Health and Development grant 1R21 HD055501-01, Baylor College of Medicine General Clinical Research Center Grant \#0942, funded by NIH M01 RR00188, and Charles A. Dana Foundation Brain Imaging Grant. The remainder of the funding support was from Texas Children's Hospital Anesthesiology Research Fund, and the Texas Children's Hospital Center for Cardiac Outcomes Research.

Received for publication Feb 18, 2009; revisions received July 16, 2009; accepted for publication Aug 10, 2009; available ahead of print Nov 12, 2009.

Address for reprints: Dean B. Andropoulos, MD, MHCM, Chief of Anesthesiology, Texas Children's Hospital, Professor, Anesthesiology and Pediatrics, Baylor College of Medicine, 6621 Fannin, WT 17417B, Houston, TX 77030 (E-mail: dra@ bcm.tmc.edu).

$0022-5223 / \$ 36.00$

Copyright (C) 2010 by The American Association for Thoracic Surgery

doi:10.1016/j.jtcvs.2009.08.022
}

attention deficit hyperactivity disorder and other cognitive and fine motor deficits. ${ }^{2}$ Creighton and colleagues ${ }^{3}$ documented that $26.4 \%$ of a cohort of 53 neonates without chromosomal abnormalities who had repair of hypoplastic left heart syndrome, transposition of the great vessels, or total anomalous pulmonary venous return had a full-scale IQ score of $<85$ at 5 years of age. Majnemer and associates ${ }^{4}$ documented gross motor delays in $49 \%$ and fine motor delays in $39 \%$ of a cohort of 94 patients tested at age 5 years, who had undergone complex congenital cardiac surgery as infants. Magnetic resonance imaging (MRI) has documented a preoperative incidence of white matter injury (WMI) or other ischemic lesions of $20 \%$ to $40 \%{ }^{5,6}$ Associations with poor neurodevelopmental outcomes include chromosomal abnormalities, particularly 22.q11.2 microdeletion (common in tetralogy of Fallot, interrupted aortic arch, and truncus arteriosus), resulting in significantly lower mental and physical development. ${ }^{7}$

Perioperative causes of neurologic injury include cerebral hypoxia/ischemia due to cyanosis, surgical or cardiopulmonary bypass $(\mathrm{CPB})$ techniques including prolonged deep hypothermic circulatory arrest (DHCA), ${ }^{8}$ cerebral emboli, 


$$
\begin{aligned}
& \text { Abbreviations and Acronyms } \\
& 2 \mathrm{~V}=\text { two ventricle } \\
& \mathrm{ACP}=\text { antegrade cerebral perfusion } \\
& \text { CHD = congenital heart disease } \\
& \mathrm{CPB}=\text { cardiopulmonary bypass } \\
& \text { DHCA }=\text { deep hypothermic circulatory arrest } \\
& \text { KIU = kallikrein inhibiting units } \\
& \text { MRI = magnetic resonance imaging } \\
& \mathrm{rSO}_{2}=\text { regional cerebral oxygen saturation } \\
& \mathrm{SpO}_{2}=\text { pulse oximetry saturation } \\
& \mathrm{SV}=\text { single ventricle } \\
& \text { TE }=\text { echo time } \\
& \text { TMS = Total Maturity Score } \\
& \mathrm{TR}=\text { relaxation time } \\
& \text { WMI = white matter injury }
\end{aligned}
$$

low cardiac output, and intercurrent events such as cardiac arrests. ${ }^{9}$ Attempts to reduce acute brain injury have included newer perfusion techniques, such as antegrade cerebral perfusion (ACP), which allow continuous delivery of oxygenated blood to the brain during CPB in neonates. ${ }^{10}$ Monitoring of cerebral oxygenation using near infrared spectroscopy and cerebral blood flow velocity using transcranial Doppler ultrasound ${ }^{11}$ have also been used as individualized strategies for continuous oxygen delivery to the brain. $\mathrm{pH}$ stat blood gas management ${ }^{12}$ and hematocrit of $25 \%$ or greater ${ }^{13}$ allow for more even brain cooling and provide greater oxygen delivery to the brain, resulting in improved neurologic outcomes. Despite these new intraoperative techniques, MRI studies have revealed a $36 \%$ to $73 \%$ incidence of new or worsening white matter or other ischemic brain lesions after neonatal cardiac surgery. ${ }^{5,6,14}$

Recently, neonates with complex congenital heart disease (CHD) have been discovered to have structural brain immaturity due to delays in myelination, cortical development, and maturation of germinal matrix and glial cell migration. ${ }^{15}$ Magnetic resonance spectroscopy also documents delayed microcellular maturation in neonates with CHD. ${ }^{16}$ This brain immaturity may predispose these infants to greater risk of brain injury, particularly WMI, which is frequently seen in premature infants with proven immature brain development. ${ }^{17-19}$

This study was undertaken to determine the incidence and severity of new MRI brain injury with high-flow CPB (maintaining full $150 \mathrm{~mL} \cdot \mathrm{kg}^{-1} \cdot \min ^{-1}$ and high-flow ACP) and monitoring cerebral oxygenation with near infrared spectroscopy. We also sought to determine the patient and procedural factors that had significant associations with brain injury, particularly brain maturation. Our hypothesis was that patients with structural brain immaturity would be more likely to have pre- and postoperative brain injury.

\section{METHODS}

This study was approved by the Baylor College of Medicine Institutional Review Board, and patients were enrolled after signed informed consent was obtained from parents. It was a prospective, observational study with a single patient cohort receiving uniform $\mathrm{CPB}$ and perioperative treatment protocols.

\section{Patient Population}

Neonates $(<30$ days of age) having cardiac surgery with hypothermic $\left(<30^{\circ} \mathrm{C}\right) \mathrm{CPB}$ for 60 minutes or greater were eligible. Both single-ventricle $(\mathrm{SV})$ and two-ventricle (2V) repairs were included. Exclusion criteria were gestational age less than 35 weeks at birth, weight less than $2.0 \mathrm{~kg}$, recognizable dysmorphic syndrome, or preoperative cardiac arrest for greater than 3 minutes.

\section{Preoperative Management}

Prostaglandin E1 infusion was used in patent ductus arteriosus-dependent systemic perfusion lesions or for patients with dextrotransposition of the great arteries with significant cyanosis manifested by prolonged peripheral oxygen saturation $\left(\mathrm{SpO}_{2}\right)<75 \%$. Patients with dextrotransposition of the great arteries with intact ventricular septum had balloon atrial septostomy.

\section{Anesthesia, Surgery, and Perfusion Protocol}

Anesthetic technique consisted of fentanyl (100-400 $\mu \mathrm{g} / \mathrm{kg}$ total dose), midazolam $(0.25-3 \mathrm{mg} / \mathrm{kg}$ total dose), and isoflurane (up to $1 \%$ end-tidal concentration before and after $\mathrm{CPB}$, and up to $3 \%$ inspired concentration in the CPB sweep gas). Vecuronium or pancuronium was used for neuromuscular blockade.

CPB technique consisted of arterial cannulation and bicaval or singleatrial venous cannulation. CPB flow rates of $150 \mathrm{~mL} \cdot \mathrm{kg}^{-1} \cdot \mathrm{min}^{-1}$ were used at all times, except for periods of DHCA, or ACP. Target mean arterial pressure was 30 to $35 \mathrm{~mm} \mathrm{Hg}$, facilitated if necessary with $\alpha$-receptor blockade with phenoxybenzamine $(0.25-0.5 \mathrm{mg} / \mathrm{kg})$ or phentolamine $(0.1-0.3$ $\mathrm{mg} / \mathrm{kg}$ ). Cooling on CPB was accomplished over 20 minutes or more. $\mathrm{pH}$ stat blood gas management was used throughout the $\mathrm{CPB}$ period. One dose of methylprednisolone $(20 \mathrm{mg} / \mathrm{kg})$ was given in the CPB prime. Aprotinin was utilized for the first 55 cases: 60,000 kallikrein inhibiting units (KIU)/kg loading dose followed by infusion of $7000 \mathrm{KIU} \cdot \mathrm{kg}^{-1} \cdot \mathrm{h}^{-1}$. A CPB circuit prime of $60,000 \mathrm{KIU} / \mathrm{kg}$ of aprotinin was given. After safety concerns about aprotinin in adult cardiac surgery were known, the last 13 cases had $\epsilon$-aminocaproic acid instead of aprotinin, at doses of $75 \mathrm{mg} / \mathrm{kg}$ intravenous load to the patient and $75 \mathrm{mg} \cdot \mathrm{kg}^{-1} \cdot \mathrm{h}^{-1}$ infusion throughout surgery, with a $75-\mathrm{mg} / \mathrm{kg}$ CPB prime dose. Hematocrit was maintained at $30 \%$ to $35 \%$ during cooling and hypothermic periods and increased to $40 \%$ to $45 \%$ during rewarming. Conventional ultrafiltration was utilized throughout the $\mathrm{CPB}$ period; post-CPB modified ultrafiltration was not used.

ACP was utilized for aortic arch reconstruction. ${ }^{10}$ A $3.5-\mathrm{mm}$ polytetrafluoroethylene graft was sutured to the right innominate artery as arterial inflow. CPB flow during ACP was adjusted to maintain cerebral blood flow velocity, measured with transcranial Doppler ultrasound, to within $10 \%$ of full $\mathrm{CPB}$ baseline, and right brain $\mathrm{rSO}_{2}>90 \%$, as described previously. ${ }^{10}$

Physiologic monitor data $\left(\mathrm{SpO}_{2}\right.$, intra-arterial pressure, heart rate, temperature, intracardiac pressures) as well as cerebral oximeter data were collected in 1-minute intervals and stored electronically for the pre-, intra- and 72-hour postoperative periods. (Bedmaster, Excel Medical Electronics, Inc, Jupiter, Fla; and Somanetics, Inc, Troy, Mich).

\section{Cerebral Oxygenation Monitoring and Treatment Protocol}

Regional cerebral oxygen saturation $\left(\mathrm{rSO}_{2}\right)$ was monitored with a sensor on the right forehead (Somanetics 5100A; Somanetics, Inc). If the $\mathrm{rSO}_{2}$ was 
less than $50 \%$, attempts were made to increase oxygen delivery to the brain or decrease oxygen consumption. ${ }^{11}$ This protocol was used throughout the preoperative, intraoperative, and 72-hour postoperative study periods. Suggested interventions included:

1. Increasing systemic cardiac output with volume infusions, afterload reduction, or inotropic support.

2. Increasing hematocrit with blood transfusion, or hemofiltration on $\mathrm{CPB}$ to $40 \%$ or greater.

3. Treating fever, with target rectal temperature $<36.5^{\circ} \mathrm{C}$, and cooling further while on $\mathrm{CPB}$.

4. Increasing $\mathrm{FiO}_{2}$, intubating the trachea and ventilating the patient to decrease work of breathing and increase oxygen delivery, increase the $\mathrm{PACO}_{2}$ to 45 to $55 \mathrm{~mm} \mathrm{Hg}$ to increase cerebral blood flow.

5. Sedation or neuromuscular blockade to decrease oxygen consumption.

6. Increasing $\mathrm{CPB}$ flow or perfusion pressure.

7. Increasing temperature-corrected $\mathrm{PACO}_{2}$ on $\mathrm{CPB}$.

The threshold of $\mathrm{rSO}_{2}<50 \%$ for intervention was chosen because of previously published data suggesting that prolonged $\mathrm{rSO}_{2}<45 \%$ in the postoperative period is associated with new postoperative MRI brain injury in neonates having stage I palliation for hypoplastic left heart syndrome. ${ }^{5}$ The priority and sequence of these interventions was left to the discretion of the attending anesthesiologist and surgeon during surgery. In the intensive care unit, the bedside nurse notified the responsible physician for $\mathrm{rSO}_{2}$ values $<50 \%$, and intervention was undertaken according to the physician's discretion using the algorithm listed above. No attempt was made to record the number of interventions and the response to interventions.

\section{Brain MRI Protocol}

Brain MRI was obtained immediately before surgery, with general endotracheal anesthesia. MRI was performed on a 1.5 - T Intera scanner (Philips Medical Systems, Best, The Netherlands), including standard T1- and T2-weighted images, diffusion-weighted imaging, and magnetic resonance spectroscopy. ${ }^{20}$ The MRI protocols are detailed in Appendix 1. Postoperative MRI was obtained when the patient was clinically stable, with a goal of 7 days postoperatively. Patients were sedated with intravenous pentobarbital, 5 to $10 \mathrm{mg} / \mathrm{kg}$. A third MRI was obtained at age 3 to 6 months, immediately before a second-stage surgery with general endotracheal anesthesia or with intravenous sedation with pentobarbital or propofol.

\section{MRI Analysis}

All MRI were evaluated by a board-certified neuroradiologist (J.V.H.), who was unaware of diagnosis or surgery. Grading of the T1-, T2-, and diffusion-weighted images was done according a modification of the scoring system devised by McQuillen and associates. ${ }^{14,20}$ (See Appendix 2.) Abnormalities were classified in 9 categories: WMI, infarction or ischemic stroke, intraparenchymal hemorrhage or hemorrhagic stroke, punctate lesions, elevated lactate on magnetic resonance spectroscopy, subdural hemorrhage, dural sinovenous thrombosis, intraventricular hemorrhage, and congenital malformations. Abnormalities in each category were scored 0 for none, 1 for mild, 2 for moderate, 3 for severe. The score in each category was multiplied by a proposed outcome significance multiplier: 3 for WMI, infarction, or intraparenchymal hemorrhage; 2 for punctate lesions or lactate; and 1 for subdural hemorrhage, dural sinovenous thrombosis, intraventricular hemorrhage, or congenital malformations. A total injury score of 0 signified no injury; a score of 1 to 5 , mild injury; 6 to 10 , moderate injury; and $>10$, severe injury. Developmental maturity of the brain was assessed from T1- and T2-weighted images using the scoring system of Childs and colleagues, ${ }^{21}$ grading myelination, cortical infolding, involution of the germinal matrix, and presence of bands of migrating glial cells to produce a Total Maturity Score (TMS). ${ }^{15}$ (See Appendix 3.)

\section{Statistical Analysis}

The primary outcome variable was the incidence of new intraparenchymal lesions, including WMI, infarction, or intraparenchymal hemorrhage on postoperative brain MRI. Using chi-square analysis with Yates correction, a sample size of 57 patients was needed to detect a $40 \%$ incidence of new postoperative lesions with a power of 0.90 and $\alpha$ level of 0.05 . This assumed a baseline incidence of WMI, infarction, or intraparenchymal hemorrhage of $10 \%$ and a postoperative incidence of $50 \%$, based on previous studies. ${ }^{5,6,14}$ For detailed analysis, patients were divided into SV and $2 \mathrm{~V}$ groups. Data were analyzed using paired $t$ test, Mann-Whitney rank sum test, Fisher exact test, or chi-square analysis as appropriate (SPSS Statistics 14.0, SPSS Corporation, Chicago, Ill).

The following preoperative variables were analyzed for association with preoperative brain injury using bivariate nonparametric Spearman correlation: SV versus $2 \mathrm{~V}$, birth weight, gestational age, Apgar scores, balloon atrial septostomy, lowest sustained $(\geq 10$ minutes total in 24 hours) preoperative $\mathrm{SpO}_{2}$, preoperative minutes of $\mathrm{rSO}_{2}<45 \%$, and brain TMS. The following intra- and postoperative variables were analyzed for association with postoperative brain injury: SV versus $2 \mathrm{~V}$; gestational age; CPB time; aortic crossclamp time; ACP time; DHCA time; total minutes of $\mathrm{rSO}_{2}<45 \%$; mean $\mathrm{rSO}_{2}$ intraoperatively and on postoperative day 1,2 , and 3 ; lowest sustained postoperative systolic and diastolic blood pressure and $\mathrm{SpO}_{2}(\geq 30$ minutes total in 72 hours); presence of a preoperative brain injury; and brain TMS (on preoperative MRI). In addition, gestational age, birth weight, TMS, brain injury on postoperative MRI, lowest sustained systolic and diastolic blood pressure, and total time at $\mathrm{rSO}_{2}<45 \%$ were tested for association with late death. All analyses of physiologic and cerebral oximeter parameters were performed using data stored digitally in Excel (Microsoft Corp, Redmond, Wash) spreadsheet files and transferred into appropriate statistical applications.

Linear regression analysis by block entry model determined association of clinical variables with preoperative and postoperative brain injury and late death, which were found on bivariate Spearman analysis to have $R>0.2$, after screening for multicollinearity. A $B$ value with $95 \%$ confidence intervals and percentage variance for explanation of the dependent variable with the final model are also reported.

\section{RESULTS}

Sixty-eight patients were enrolled in the study from November 2005 until August 2008. Data from the pre-, intra-, and postoperative periods are presented in Tables 1 and 2. The patients in the $2 \mathrm{~V}$ group had a higher birth weight, lower 1-minute Apgar scores, and lower preoperative $\mathrm{SpO}_{2}$, and more patients had balloon atrial septostomy. Significant differences in bypass management included fewer patients receiving ACP in the $2 \mathrm{~V}$ group. Postoperatively, patients in the $2 \mathrm{~V}$ group had almost no $\mathrm{rSO}_{2}<45 \%$, versus a significant incidence and duration of low $\mathrm{rSO}_{2}$ in the patients in the SV group. Sixty-six of 68 patients were 30-day in-hospital survivors (97.1\%). One patient in the SV group required postoperative extracorporeal membrane oxygenation and died 8 days postoperatively. Another patient in the SV group died of sudden cardiorespiratory arrest in hospital 19 days postoperatively after apparent excellent full surgical recovery. There were 6 additional late deaths in the SV group: 5 patients who died before their second stage surgery between 2 and 6 months of age, of cardiorespiratory arrest suffered in 
TABLE 1. Preoperative patient data

\begin{tabular}{|c|c|c|c|}
\hline Parameter & $\begin{array}{l}\text { Single ventricle } \\
\quad(\mathbf{n}=\mathbf{3 6})\end{array}$ & $\begin{array}{l}\text { Two ventricle } \\
\quad(\mathbf{n}=\mathbf{3 2})\end{array}$ & $\begin{array}{c}P \\
\text { value }\end{array}$ \\
\hline \multicolumn{4}{|l|}{ Anatomic diagnosis } \\
\hline HLHS & 35 & NA & NA \\
\hline TGA, DILV & 1 & NA & NA \\
\hline TGA & NA & 21 & NA \\
\hline Truncus arteriosus & NA & 5 & NA \\
\hline IAA, VSD & NA & 6 & NA \\
\hline Birth weight $(\mathrm{kg})$ & $3.01 \pm 0.33$ & $3.27 \pm 0.54$ & $.02 *$ \\
\hline Gestational age (wk) & $38.3 \pm 1.2$ & $38.8 \pm 1.3$ & .10 \\
\hline Head circumference $(\mathrm{cm})$ & $33.3 \pm 1.6$ & $33.8 \pm 1.3$ & .11 \\
\hline Prenatal diagnosis, $\mathrm{n}(\%)$ & $17(47)$ & $13(44)$ & .97 \\
\hline Cesarean delivery, n (\%) & $13(36)$ & $13(41)$ & .90 \\
\hline 1-min Apgar score & $7.9 \pm 1.3$ & $7.2 \pm 1.5$ & $.05^{*}$ \\
\hline 5-min Apgar score & $8.8 \pm 0.5$ & $8.3 \pm 1.0$ & $.01 *$ \\
\hline $\begin{array}{l}\text { Balloon atrial } \\
\text { septostomy, n (\%) }\end{array}$ & $1(3)$ & $18(56)$ & $<.001^{*}$ \\
\hline $\begin{array}{l}\text { Lowest } \mathrm{SpO}_{2} \text { (sustained } 10 \\
\text { min) }\end{array}$ & $88 \pm 4$ & $81 \pm 10$ & $<.001^{*}$ \\
\hline $\begin{array}{l}\text { Lowest } \mathrm{rSO}_{2} \text { (sustained } 10 \\
\text { min) }\end{array}$ & $53 \pm 8$ & $51 \pm 12$ & .25 \\
\hline Preoperative $\mathrm{rSO}_{2} \min <45 \%$ & $28 \pm 69$ & $78 \pm 207$ & .18 \\
\hline Preoperative $\mathrm{rSO}_{2} \min \geq 45 \%$ & $918 \pm 347$ & $783 \pm 272$ & .09 \\
\hline
\end{tabular}

DILV, Double inlet left ventricle; $H L H S$, hypoplastic left heart syndrome; IAA, interrupted aortic arch; $r \mathrm{SO}_{2}$, regional brain oxygen saturation; $\mathrm{SpO}_{2}$, pulse oximetry saturation; $T G A$, transposition great arteries; $V S D$, ventricular septal defect. Data expressed as means \pm standard deviation. $* P<.05$ by $t$ test.

hospital after readmission (2) or at an outside hospital (3), and 1 who died in-hospital after bidirectional cavopulmonary connection surgery of Pseudomonas aeruginosa septic shock.

MRI data from the pre- and 7-day postoperative scans are presented in Table 3. Sixty-eight patients had a first MRI and 67 patients had the second MRI, $56(84 \%)$ at 7 to 10 days postoperatively. For the primary outcome variable, there was a $36 \%$ incidence of new WMI, infarction, or hemorrhage, with $45 \%$ of the SV group having these new findings versus $25 \%$ of $2 \mathrm{~V}$ group $(P=.13)$. For other important outcome variables, there was a $15 \%$ incidence of new postoperative WMI ( $23 \% \mathrm{SV}$ vs $6 \% 2 \mathrm{~V}, P=.09)$. Six patients had resolution of mild WMI between the pre- and postoperative scans. The severity of postoperative brain injury, estimated by our severity of injury score, was $3.5 \pm$ 3.9 , and was not different between $\mathrm{SV}$ and $2 \mathrm{~V}$ groups; however, this represented a significant increase from a preoperative injury score of $2.0 \pm 2.7$ for the entire cohort $(P=$ .012). Figures 1 and 2 display representative patients' MRI scans.

Secondary outcome variables included preoperative WMI, infarction, or hemorrhage, seen in $28 \%$ of patients (28\% in both SV and $2 \mathrm{~V}$ groups). Preoperative WMI was observed in $16 \%(13 \% \mathrm{SV}$ vs $19 \% 2 \mathrm{~V}, P=.83)$. Late death was observed in $7 / 35$ patients in the $\mathrm{SV}$ group versus none of 32 in the $2 \mathrm{~V}$ group $(P=.01)$.
TABLE 2. Operative and postoperative patient data

\begin{tabular}{|c|c|c|c|}
\hline Parameter & $\begin{array}{c}\text { SV } \\
(\mathbf{n}=\mathbf{3 6})\end{array}$ & $\begin{array}{c}2 \mathrm{~V} \\
(\mathrm{n}=\mathbf{3 2})\end{array}$ & $\begin{array}{c}P \\
\text { value }\end{array}$ \\
\hline Age (d) & $7(5-10.5)$ & $8(5.5-13.5)$ & .33 \\
\hline Weight $(\mathrm{kg})$ & $3.02 \pm 0.36$ & $3.30 \pm 0.52$ & $.011^{*}$ \\
\hline \multicolumn{4}{|l|}{ Operation } \\
\hline Norwood stage I palliation & 35 & & NA \\
\hline $\mathrm{ASO}, \mathrm{AAA}, \mathrm{PAB}$ & 1 & & NA \\
\hline ASO & 0 & 21 & NA \\
\hline Truncus arteriosus repair & 0 & 5 & NA \\
\hline AAA, VSD repair & 0 & 6 & NA \\
\hline $\begin{array}{l}\text { Preoperative mechanical } \\
\text { ventilation, } \mathrm{n}(\%)\end{array}$ & 7 (19) & $6(19)$ & .81 \\
\hline $\mathrm{CPB}$ time (min) & $216 \pm 58$ & $220 \pm 68$ & .77 \\
\hline AoXcl time (min) & $103 \pm 36$ & $128 \pm 44$ & $.01 *$ \\
\hline Lowest temperature $\left({ }^{\circ} \mathrm{C}\right)$ & $17.5 \pm 0.7$ & $23.5 \pm 3.6$ & $<.001 *$ \\
\hline $\begin{array}{l}\text { Hematocrit during } \\
\text { hypothermia }(\%)\end{array}$ & $30.2 \pm 2.2$ & $31.2 \pm 1.7$ & .07 \\
\hline DHCA time, min (no. of patients) & $13 \pm 8(30)$ & $11 \pm 5(4)$ & .60 \\
\hline ACP time, min (no. of patients) & $76 \pm 20(36)$ & $27 \pm 17(7)$ & $<.001 *$ \\
\hline $\begin{array}{l}\text { ACP flow rates, } \mathrm{mL} \cdot \mathrm{kg}^{-1} \cdot \mathrm{min}^{-1} \\
\quad \text { (No. of patients) }\end{array}$ & $56 \pm 10(36)$ & $63 \pm 13(7)$ & .08 \\
\hline Intraoperative $\mathrm{rSO}_{2} \min <45 \%$ & $45 \pm 49$ & $15 \pm 31$ & .004 \\
\hline Intraoperative $\mathrm{rSO}_{2} \min \geq 45 \%$ & $410 \pm 105$ & $396 \pm 117$ & .60 \\
\hline Postoperative $\mathrm{rSO}_{2} \min <45 \%$ & $287 \pm 408$ & $1 \pm 3$ & $<.001$ \\
\hline Postoperative $\mathrm{rSO}_{2} \min \geq 45 \%$ & $3779 \pm 582$ & $4136 \pm 326$ & .003 \\
\hline
\end{tabular}

The most important independent variable tested was preoperative TMS, according to our study hypothesis. The preoperative TMS was $11.8 \pm 1.5$ in the SV group and $11.8 \pm 1.0$ in the $2 \mathrm{~V}$ group. After multivariable analysis, low TMS (increasing brain immaturity) was associated with preoperative WMI $(P=.002)$ and also postoperative late death $(P=.008)$. Low brain maturity rated using the TMS score was associated with increased severity of postoperative brain injury, with 7 of 13 patients with TMS $\leq 10$ (equal to brain maturity of 35 weeks' gestational age or less $^{21}$ ) having a postoperative brain injury score of 6 or above (moderate injury) versus only 10 of 54 with TMS > $10(P=.01$, chi-square $)$. In addition, preoperative WMI was more likely with TMS $<10(5 / 13$ vs $6 / 55, P=.03$, chi-square), as was postoperative WMI (6/13 vs $9 / 54$, $P=.05$, chi-square).

We considered sustained cerebral desaturation (total minutes of $\mathrm{rSO}_{2}<45 \%$ in the intra- and postoperative periods) an important independent variable, but did not find an association between this parameter and any measure of postoperative MRI brain injury. Eighteen of 35 patients in the $\mathrm{SV}$ group had greater than 240 minutes of $\mathrm{rSO}_{2}<45 \%$ in the intra- and postoperative periods; 11 of these $18 \mathrm{had}$ 
TABLE 3. Standard MRI data, pre- and 7-d postoperative MRI scans

\begin{tabular}{|c|c|c|c|c|}
\hline Parameter & $\begin{array}{c}\text { SV } \\
(\mathbf{n}=\mathbf{3 6})\end{array}$ & $\begin{array}{c}2 \mathrm{~V} \\
(\mathrm{n}=32)\end{array}$ & $\begin{array}{l}P \text { value, } \\
\text { SV vs } 2 \text { V }\end{array}$ & Total \\
\hline MRI postoperative $\mathrm{d}$ & $7(7-9)$ & $7(7-9)$ & $>.9$ & $7(7-9)$ \\
\hline $\begin{array}{l}\text { Preoperative WMI, infarct, or } \\
\text { IP hemorrhage, n }(\%)\end{array}$ & $7(19)$ & $4(13)$ & .83 & $11(28)$ \\
\hline Preoperative WMI, n (\%) & $5(14)$ & $6(19)$ & .83 & $11(16)$ \\
\hline Preoperative infarct, $\mathrm{n}(\%)$ & $5(14)$ & $7(22)$ & .59 & $12(18)$ \\
\hline $\begin{array}{l}\text { Preoperative IP hemorrhage, } \\
\text { n (\%) }\end{array}$ & 0 & 0 & $>.9$ & 0 \\
\hline $\begin{array}{l}\text { Preoperative punctate } \\
\quad \text { lesions, } \mathrm{n}(\%)\end{array}$ & $3(8)$ & $1(3)$ & .62 & $4(6)$ \\
\hline $\begin{array}{l}\text { Preoperative MRS elevated } \\
\text { lactate, } n(\%)\end{array}$ & $2(6)$ & $2(6)$ & $>.9$ & $4(6)$ \\
\hline Preoperative SDH, n (\%) & $11(31)$ & $3(9)$ & $.05^{*}$ & $14(21)$ \\
\hline Preoperative DVST, n (\%) & $1(3)$ & $1(3)$ & $>.9$ & $2(3)$ \\
\hline Preoperative IVH, n (\%) & 0 & $2(6)$ & .22 & $2(3)$ \\
\hline $\begin{array}{l}\text { Any preoperative } \\
\text { finding, } \mathrm{n}(\%)\end{array}$ & $19(53)$ & $19(59)$ & .76 & $38(57)$ \\
\hline $\begin{array}{l}\text { 7-d postoperative WMI, } \\
\text { infarction, or IP } \\
\text { hemorrhage, } \mathrm{n}(\%)\end{array}$ & $22(63)$ & $14(44)$ & .19 & $36(54)$ \\
\hline 7-d postoperative WMI, $\mathrm{n}(\%)$ & $13(37) \dagger$ & $2(6)$ & $.006^{*}$ & $15(22)$ \\
\hline $\begin{array}{l}\text { 7-d postoperative } \\
\text { infarct, } \mathrm{n}(\%)\end{array}$ & $11(31)$ & $11(34)$ & $>.9$ & $22(33)$ \\
\hline $\begin{array}{l}\text { 7-d postoperative IP } \\
\text { hemorrhage, } \mathrm{n}(\%)\end{array}$ & $3(9)$ & $2(6)$ & $>.9$ & $5(8)$ \\
\hline $\begin{array}{l}\text { 7-d postoperative punctate } \\
\text { lesions, } \mathrm{n}(\%)\end{array}$ & $6(17)$ & $10(31) \dagger$ & .29 & $16(24) \ddagger$ \\
\hline $\begin{array}{l}\text { 7-d postoperative MRS } \\
\text { elevated lactate, } n(\%)\end{array}$ & 0 & 0 & $>.9$ & 0 \\
\hline 7-d postoperative SDH, n (\%) & $3(8) \dagger$ & $7(22)$ & .18 & $10(15)$ \\
\hline $\begin{array}{l}\text { 7-d postoperative DVST, } \\
\text { n }(\%)\end{array}$ & $3(9)$ & $4(13)$ & .70 & $7(11)$ \\
\hline 7-d postoperative IVH, n (\%) & $1(3)$ & $3(9)$ & .34 & $4(6)$ \\
\hline $\begin{array}{l}\text { Any } 7-\mathrm{d} \text { postoperative } \\
\text { finding, } \mathrm{n}(\%)\end{array}$ & $23(66)$ & $20(63)$ & .99 & $43(65)$ \\
\hline $\begin{array}{l}\text { New 7-d postoperative WMI, } \\
\text { infarct, or IP hemorrhage, } \\
n(\%)\end{array}$ & $16(45)$ & $8(25)$ & .13 & $24(36)$ \\
\hline New 7-d postoperative WMI & $8(23)$ & $2(6)$ & .09 & $10(15)$ \\
\hline $\begin{array}{l}\text { Any new } 7-\mathrm{d} \text { postoperative } \\
\text { finding, } \mathrm{n}(\%)\end{array}$ & $18(51)$ & $20(63)$ & .51 & $38(58)$ \\
\hline $\begin{array}{l}\text { Any pre- or } 7-\mathrm{d} \text { postoperative } \\
\text { finding, } \mathrm{n}(\%)\end{array}$ & $26(72)$ & $25(78)$ & .78 & $51(76)$ \\
\hline $\begin{array}{l}\text { Congenital malformations, } \\
\mathrm{n}(\%)\end{array}$ & 0 & $2(6)$ & .22 & $2(3)$ \\
\hline Preoperative MRI TMS & $11.8 \pm 1.51$ & $11.8 \pm 1.0$ & .93 & $11.8 \pm 1.3$ \\
\hline $\begin{array}{l}\text { Patients with } \mathrm{TMS} \leq 10, \\
\mathrm{n}(\%)\end{array}$ & $8(22)$ & $6(19)$ & .96 & $14(21)$ \\
\hline $\begin{array}{l}\text { Preoperative total MRI } \\
\text { injury score }\end{array}$ & $1.8 \pm 2.6$ & $2.3 \pm 2.8$ & .47 & $2.0 \pm 2.7$ \\
\hline $\begin{array}{l}\text { 7-d postoperative total } \\
\text { MRI injury score }\end{array}$ & $3.8 \pm 4.2 \dagger$ & $3.2 \pm 3.7$ & .57 & $3.5 \pm 3.9 \ddagger$ \\
\hline
\end{tabular}

TABLE 3. Continued

\begin{tabular}{|c|c|c|c|c|}
\hline Parameter & $\begin{array}{c}\text { SV } \\
(\mathbf{n}=\mathbf{3 6})\end{array}$ & $\begin{array}{c}2 \mathrm{~V} \\
(\mathrm{n}=32)\end{array}$ & $\begin{array}{l}P \text { value, } \\
\text { SV vs } 2 \text { V }\end{array}$ & Total \\
\hline $\begin{array}{l}\text { re/postop change in } \\
\text { total MRI injury score }\end{array}$ & $9 \pm 3.2$ & $0.9 \pm 3.2$ & .22 & $1.5 \pm 3.2$ \\
\hline \multicolumn{5}{|c|}{$\begin{array}{l}D V S T \text {, Dural sinovenous thrombosis; } I P \text {, intraparenchymal; } I V H \text {, intraventricular } \\
\text { hemorrhage; } M R S \text {, magnetic resonance spectroscopy; } S D H \text {, subdural hemorrhage; } \\
T M S \text {, Total Maturity Score; } W M I \text {, white matter injury. Data expressed as numbers } \\
\text { of patients and percentages for MRI findings, and median days ( } 25 \text { th- } 75 \text { th percentile } \\
\text { interquartile range) for MRI days postoperatively, or means } \pm \text { standard deviation for } \\
\text { numerical scores. } P \text { values are between groups. } * P \leq .05 \text { for between-group differ- } \\
\text { ences. } \dagger P \leq .05 \text { for pre- to postoperative difference within groups. } \ddagger P \leq .05 \text { for } \\
\text { pre- to postoperative difference for both groups combined. }\end{array}$} \\
\hline
\end{tabular}

new postoperative MRI lesions, versus 8 of 17 who did not have prolonged low $\mathrm{rSO}_{2}(P=.62$, chi-square). No patient in the $2 \mathrm{~V}$ group had more than 120 minutes of $\mathrm{rSO}_{2}<45 \%$ in the intra-and postoperative periods; 17 of $32 \mathrm{had}$ no $\mathrm{rSO}_{2}$ minutes $<45 \%$.

SV diagnosis was another important independent variable and was associated with the presence of postoperative WMI $(P=.02)$ and also with late death $(P=.04)$. Of all other independent variables tested, there was an association of new postoperative WMI/infarction/hemorrhage with low sustained diastolic blood pressure $(P=.039)$.The initial Spearman bivariate analyses, complete final linear regression models for preoperative MRI injury, presence of postoperative MRI injury, and new postoperative MRI injury are reported in Tables 4 to 6 .

The third MRI was completed on 45 patients; Appendix 4 reports the MRI findings. New findings were seen in $27 \%$ of patients, and a total of $29 \%$ had any abnormality detected. Fifty-eight percent of patients had partial or complete resolution of findings from the first or second MRI.

\section{DISCUSSION}

The major new finding in this study is that brain immaturity in neonates with CHD is associated with both pre- and postoperative brain injury, particularly WMI. Our patients exhibited an increased incidence of brain immaturity by TMS score. The mean TMS for both groups was 11.8 (equal to 38 weeks' gestational age for brain maturation), and the number of patients with TMS $\leq 10$ (equal to brain maturity of 35 weeks' gestational age or less ${ }^{21}$ ) was not different between groups. However, 14 of 68 patients $(21 \%)$ had TMS $\leq 10$, but only 4 of $68(6 \%)$ had gestational age less than 36 weeks. In a normal population, these proportions should be similar, but are significantly different in this CHD population $(P=.023$, chi-square).

Brain injury on MRI from brain immaturity is also found among premature infants, in whom noncystic WMI on MRI is the primary brain injury in the perinatal and early neonatal period. ${ }^{17}$ The WMI in premature infants is manifest by focal lesions, white matter volume loss, thinning corpus callosum, and diffuse, excessive signal intensity. ${ }^{16}$ Immature 

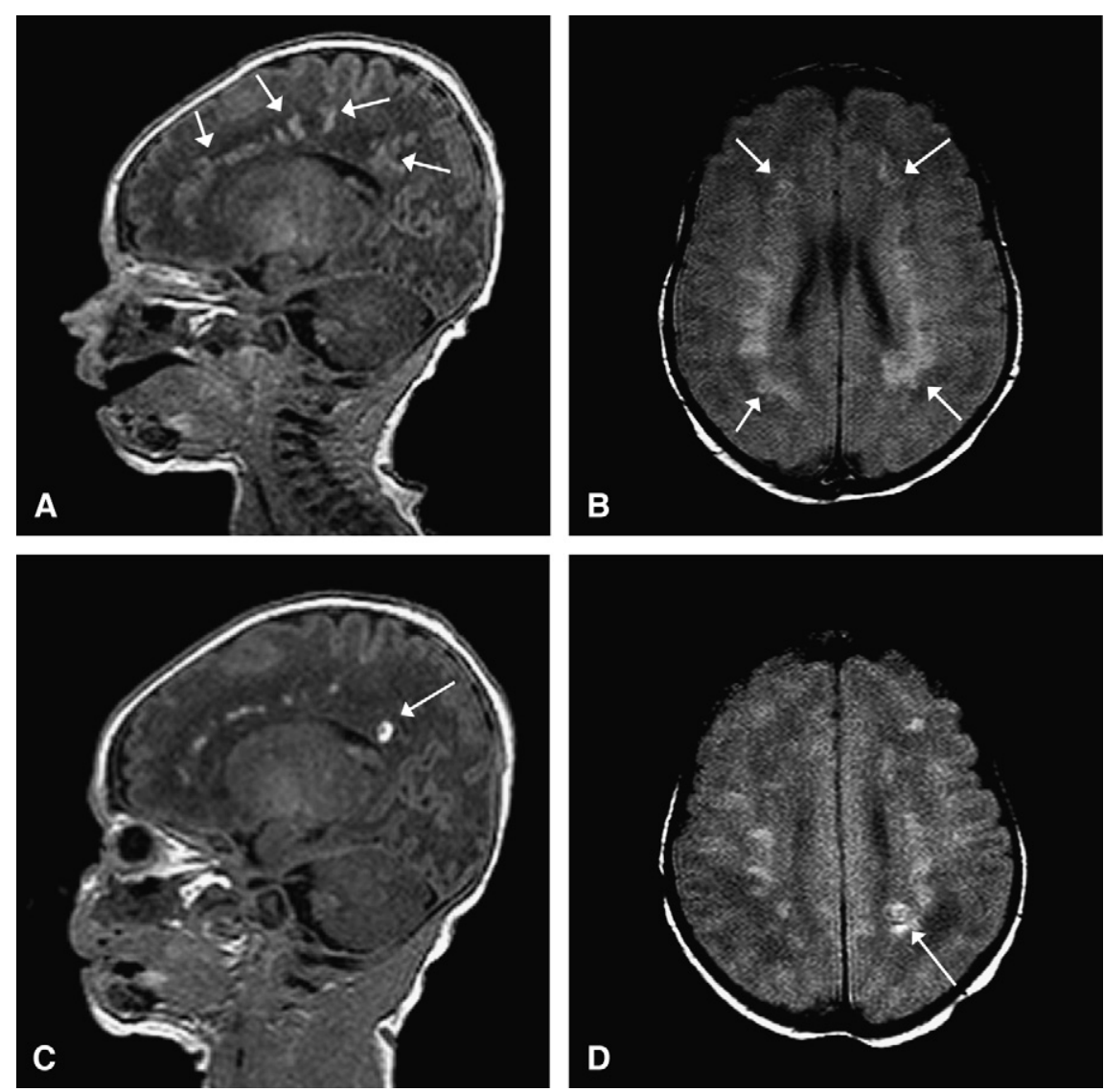

FIGURE 1. A, Preoperative sagittal T1-weighted magnetic resonance image (MRI) of a 35-week gestational-age infant with hypoplastic left heart syndrome. Extensive white matter injury (WMI) is present in the periventricular areas (arrows). B, Preoperative axial proton-density T2-weighted image. Again note extensive WMI (arrows). C, Seven-day postoperative T1 sagittal MRI after Norwood stage I palliation. Note new intraparenchymal/intraventricular hemorrhage and infarction in the left peritrigonal region (arrow). D, Proton density T2-weighted image. Again note WMI and new hemorrhage (arrow). This patient had the single highest injury score on both preoperative and postoperative MRI injury scale, at 11 points preoperatively and 21 points postoperatively. Brain total maturity score was 8, equivalent to a 33-week gestational age infant. (Refer to MRI scoring table in Appendix 3.)

oligodendrocyte white matter precursors in the rapidly developing premature neonatal brain are vulnerable to injury from hypoxia-ischemia. ${ }^{18,19}$ The peak numbers of these immature oligodendrocytes is at 23 to 32 weeks, which corresponds to the peak period of WMI in premature infants. ${ }^{22}$ Patients with CHD and immature brains could thus have their period of peak vulnerability extended to later than 32 weeks, into the period when neonatal cardiac surgery with bypass is commonly performed. Inflammation associated with pre- or postnatal infections also damages white matter in premature infants ${ }^{18}$; it is possible that the inflammatory response from $\mathrm{CPB}$ contributes to the WMI in CHD patients. ${ }^{23}$

The neurodevelopmental delays in both CHD and in premature infants are qualitatively similar and include attention deficit disorder, problems with language and fine motor function, and visual-motor integration. ${ }^{2}$ These problems may be explained by a common mechanism of brain injury, namely WMI. Galli and colleagues ${ }^{24}$ also found that WMI is frequent in neonates with CHD having surgery, observing a 54\% incidence of WMI on postoperative brain MRI versus only $6 \%$ in infants aged 1 to 6 months at the time of surgery. ${ }^{24}$ In another important finding from our study, brain immaturity was associated with late death in our SV cohort, suggesting that this factor could also play a role in the pathophysiology of these patients' death.

We found a $36 \%$ incidence of new acute postoperative MRI changes consisting of WMI, infarction, and intraparenchymal hemorrhage; $15 \%$ of patients had new WMI. In previous studies, Mahle and associates ${ }^{6}$ reported 24 neonates receiving pre- and postoperative brain MRI after cardiac surgery: $67 \%$ of patients had new postoperative brain lesions, including $42 \%$ with new WMI. Eighty-eight percent of these patients were exposed to DHCA, and lowflow $\mathrm{CPB}$ was used in the remainder, with a median DHCA time of 50 minutes. Dent and colleagues ${ }^{5}$ studied 15 neonates having Norwood stage I palliation with ACP, and 11 patients $(73 \%)$ had new lesions, including $47 \%$ with WMI, on postoperative MRI. Compared with patients 

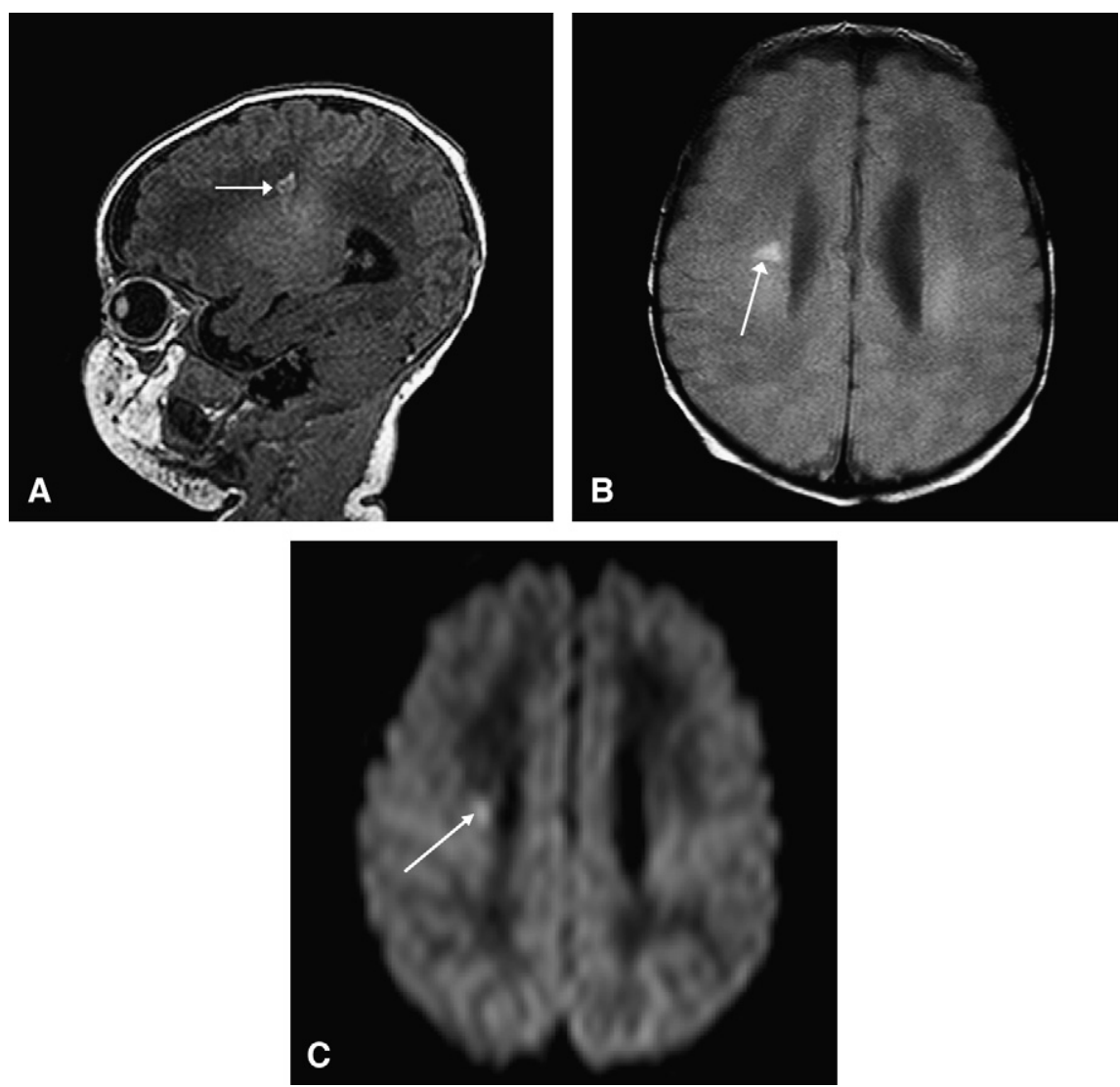

FIGURE 2. A, New postoperative infarction (white arrow) in a patient after Norwood stage I palliation for hypoplastic left heart syndrome, on T1-weighted sagittal imaging in the right posterior frontoparietal deep white matter, and extending to the lentiform nucleus, measuring $5 \times 7 \mathrm{~mm}$. B, T2-weighted image. C, Matching area of restricted diffusion (white arrow).

TABLE 4. Nonparametric Spearman bivariate and multivariate linear regression correlations with brain injury: Preoperative brain injury

\begin{tabular}{|c|c|c|c|c|}
\hline Independent variable & $\begin{array}{c}\text { Bivariate dependent- } \\
\text { variable } R \text { value: WMI }\end{array}$ & $\begin{array}{l}\text { Multivariate } B \text { value } \\
(95 \% \mathrm{CI}), P \text { value }\end{array}$ & $\begin{array}{c}\text { Bivariate dependent- } \\
\text { variable } R \text { value: WMI/ } \\
\text { hemorrhage/ infarction }\end{array}$ & $\begin{array}{c}\text { Multivariate } B \text { value } \\
(95 \% \mathrm{CI}), P \text { value }\end{array}$ \\
\hline $\mathrm{SV} / 2 \mathrm{~V}$ & 0.055 & - & -0.005 & - \\
\hline GA & -0.165 & - & -0.164 & - \\
\hline BW & -0.055 & - & -0.075 & - \\
\hline 1-min Apgar & -0.024 & - & 0.042 & - \\
\hline 5-min Apgar & -0.061 & - & 0.104 & - \\
\hline BAS Y/N & 0.070 & - & 0.045 & - \\
\hline Lowest $\mathrm{SpO}_{2}$ sustained $10 \mathrm{~min}$ & $-0.209 *$ & $\begin{array}{c}-0.011(-0.028-0.007) \\
P=.224\end{array}$ & -0.082 & - \\
\hline Min $\mathrm{rSO}_{2}<45 \%$ & -0.112 & - & -0.197 & - \\
\hline TMS & $-0.232 *$ & $\begin{array}{c}-0.176(-0.284-0.068), \\
P=.002\end{array}$ & -0.147 & - \\
\hline $\begin{array}{l}\text { Percentage of variance } \\
\text { explained by the final } \\
\text { block entry linear } \\
\text { regression model }\end{array}$ & - & 12.6 & - & NA \\
\hline
\end{tabular}

$2 \mathrm{~V}$, Two ventricle; $\mathrm{BW}$, birth weight; $\mathrm{CI}$, confidence interval; $\mathrm{GA}$, gestational age; $r \mathrm{SO}_{2}$, regional brain oxygen saturation; $\mathrm{SpO}_{2}$, pulse oximetry saturation; $\mathrm{SV}$, single ventricle; $T M S$, Total Maturity Score; WMI, white matter injury; Spearman, Spearman correlation test. *Entered into linear regression analysis by block entry method. 
TABLE 5. Nonparametric Spearman bivariate and multivariate linear regression correlations with brain injury: Presence of postoperative brain injury

\begin{tabular}{|c|c|c|c|c|}
\hline Independent variable & $\begin{array}{c}\text { Bivariate } \\
\text { dependent-variable } \\
R \text { value: Presence } \\
\text { of postoperative WMI }\end{array}$ & $\begin{array}{c}\text { Multivariate } B \text { value } \\
(95 \% \text { CI }), P \text { value: } \\
\text { Presence of postoperative } \\
\text { WMI }\end{array}$ & $\begin{array}{c}\text { Bivariate dependent-variable } \\
R \text { value: Presence } \\
\text { of postoperative WMI/ } \\
\text { hemorrhage/infarction }\end{array}$ & $\begin{array}{c}\text { Multivariate } B \text { value }(95 \% \\
\text { CI), } P \text { value: Presence of } \\
\text { postoperative WMI/ } \\
\text { hemorrhage/infarction }\end{array}$ \\
\hline $\mathrm{SV} / 2 \mathrm{~V}$ & $-0.328 *$ & $\begin{array}{c}-0.458(-0.749-0.168), \\
P=.002\end{array}$ & -0.191 & - \\
\hline GA & -0.095 & - & -0.102 & - \\
\hline TMS & -0.097 & - & -0.095 & - \\
\hline Preop MRI WMI & $0.412 *$ & $\begin{array}{c}0.556(0.314-0.797), \\
P<.001\end{array}$ & NA & NA \\
\hline Preop MRI WMI/hem/inf & NA & NA & $0.252 *$ & $\begin{array}{c}0.275(0.015-0.535), \\
P=.039\end{array}$ \\
\hline CPB time & 0.085 & - & 0.065 & - \\
\hline Aoxcl time & $-0.297 \dagger$ & - & -0.190 & - \\
\hline ACP time & $0.230 \dagger$ & - & 0.126 & - \\
\hline DHCA time & $0.215 \dagger$ & - & 0.082 & - \\
\hline $\begin{array}{l}\text { Postop low SBP sustained } \\
30 \mathrm{~min}\end{array}$ & -0.120 & - & 0.005 & - \\
\hline $\begin{array}{l}\text { Postop low DBP sustained } \\
30 \mathrm{~min}\end{array}$ & -0.019 & - & 0.190 & - \\
\hline $\begin{array}{l}\text { Intra/postop } \mathrm{rSO}_{2}<45 \% \\
\text { total min }\end{array}$ & 0.133 & - & 0.191 & - \\
\hline $\begin{array}{l}\text { Postop low } \mathrm{SpO}_{2} \text { sustained } \\
\quad 30 \mathrm{~min}\end{array}$ & -0.160 & - & -0.140 & - \\
\hline $\begin{array}{l}\text { Percentage of variance } \\
\text { explained by the final } \\
\text { block entry linear } \\
\text { regression model }\end{array}$ & - & 30.2 & - & 8.6 \\
\hline
\end{tabular}

$2 V$, Two ventricle; $A C P$, antegrade cerebral perfusion; $A o x c l$, aortic crossclamp time; $C I$, confidence interval; $C P B$, cardiopulmonary bypass; $D B P$, diastolic blood pressure; $D H C A$, deep hypothermic circulatory arrest; $G A$, gestational age; $M R I$, magnetic resonance imaging; $r \mathrm{SO}_{2}$, regional brain oxygen saturation; $S B P$, systolic blood pressure; $S p O_{2}$, pulse oximetry saturation; $S V$, single ventricle; $T M S$, Total Maturity Score; $W M I$, white matter injury; Spearman, Spearman correlation test. Spearman correlation test. *Entered into linear regression analysis by block entry method. †Failed multicollinearity screening.

in the current study, whose mean ACP flow rate was $57 \mathrm{~mL}$. $\mathrm{kg}^{-1} \cdot \mathrm{min}^{-1}$, the ACP flow rate in Dent's study was less than half. In 53 neonates having cardiac surgery with pre- and postoperative MRI, McQuillen and coworkers ${ }^{14}$ also found that $36 \%$ of their 53 patients had some form of new postoperative brain injury; their patients had a $26 \%$ incidence of new WMI on postoperative MRI. DHCA use was limited in this cohort, and they found low-flow ACP was associated with new postoperative WMI.

We did not find an association of prolonged low $\mathrm{rSO}_{2}$ $<45 \%$ or mean $\mathrm{rSO}_{2}$ in the intraoperative or postoperative periods with postoperative brain injury in this patient cohort, differing from previous studies. ${ }^{5,14}$ This was unexpected, and the potential explanations include the possibility that the patients who remained at low $\mathrm{rSO}_{2}$ values may have had other protective factors (ie, hypoxic preconditioning). In addition, the $\mathrm{rSO}_{2}$ threshold for brain injury may have been lower than $45 \%$ in our patients; we did not test for lower thresholds, nor did we assess $\mathrm{rSO}_{2}$ area under the curve.

Using our full MRI injury scale, we found a high overall incidence of patients with any abnormality on MRI scans (56\% preoperative, $63 \%$ postoperative, $75 \%$ overall).
This high incidence is due to the fact that we devised a comprehensive scoring system categorizing all detected abnormalities, even minor findings not included by other investigators. ${ }^{5,6,14,24}$ Twenty-five of $43(58 \%)$ patients with postoperative findings had a mild injury (brain injury score $<6), 15(35 \%)$ had a moderate injury (brain injury score $6-10)$, and only $3(7 \%)$ a severe injury (brain injury score $>10$ ).

Studies of preterm and term infants without CHD have demonstrated that hypoxic-ischemic changes on MRI such as WMI are predictive of long-term neurodevelopmental abnormalities, ${ }^{25}$ but to date no studies have established the association between early brain MRI changes and later abnormal neurodevelopmental outcomes in the neonatal cardiac population. There is an urgent need to determine if there is such an association in the CHD population, to determine whether MRI will be an acceptable surrogate, in order to quickly determine the effects of any interventions to improve neurodevelopmental status. ${ }^{26}$ Our own data, and one other report that many changes resolve by 3 to 6 months, ${ }^{24}$ suggest the possibility that neonatal brain plasticity may allow remodeling after early insults. 
TABLE 6. Nonparametric Spearman bivariate and multivariate linear regression correlations with brain injury: New postoperative brain injury

\begin{tabular}{|c|c|c|c|c|}
\hline Independent variable & $\begin{array}{c}\text { Bivariate dependent- } \\
\text { variable } R \text { value: New WMI }\end{array}$ & $\begin{array}{l}\text { Multivariate } B \text { value }(95 \% \\
\text { CI), } P \text { value for new WMI }\end{array}$ & $\begin{array}{c}\text { Bivariate dependent- } \\
\text { variable } R \text { value: New WMI/ } \\
\text { hemorrhage/infarction }\end{array}$ & $\begin{array}{c}\text { Multivariate } B \text { value }(95 \% \\
\text { CI), } P \text { value for new WMI/ } \\
\text { hemorrhage/infarction }\end{array}$ \\
\hline $\mathrm{SV} / 2 \mathrm{~V}$ & -0.182 & - & 0.112 & - \\
\hline GA & -0.105 & - & -0.110 & - \\
\hline TMS & 0.034 & - & 0.029 & - \\
\hline Preop MRI WMI & 0.094 & - & $0.297^{*}$ & $\begin{array}{c}0.256(0.066-0.447) \\
P=.009\end{array}$ \\
\hline Preop MRI WMI/hem/inf & -0.100 & - & 0.082 & - \\
\hline CPB time & 0.042 & - & 0.194 & - \\
\hline Aoxcl time & -0.162 & - & 0.016 & - \\
\hline ACP time & 0.085 & - & -0.170 & - \\
\hline DHCA time & 0.120 & - & 0.012 & - \\
\hline $\begin{array}{l}\text { Postop low SBP sustained } \\
30 \mathrm{~min}\end{array}$ & -0.097 & - & -0.083 & - \\
\hline $\begin{array}{l}\text { Postop low DBP sustained } \\
30 \mathrm{~min}\end{array}$ & 0.109 & - & $0.226^{*}$ & $\begin{array}{c}0.034(0.002-0.067) \\
P=.039\end{array}$ \\
\hline $\begin{array}{l}\text { Intra/postop } \mathrm{rSO}_{2}<45 \% \text { total } \\
\quad \min \end{array}$ & 0.052 & - & 0.086 & - \\
\hline $\begin{array}{l}\text { Postop low } \mathrm{SpO}_{2} \text { sustained } \\
30 \mathrm{~min}\end{array}$ & -0.119 & - & 0.189 & - \\
\hline $\begin{array}{l}\text { Percentage of variance } \\
\text { explained by the final } \\
\text { block entry linear } \\
\text { regression model }\end{array}$ & - & - & - & 14.7 \\
\hline
\end{tabular}

This study has several important limitations. Although the Childs TMS is a validated scale to assess structural brain maturity in infants with a gestational age of 23 to 41 weeks, we did not have our own concurrent normal control population studied on the same MRI scanner, with TMS assigned by the same neuroradiologist. Although our patients' incidence and severity of new postoperative brain injury may be lower than in previous reports, judgments about the superiority of our bypass and neuromonitoring techniques cannot be made from this study because we did not have a control group using alternate methods (ie, a primary DHCA strategy with no neurologic monitoring). Additionally, we do not yet have sufficient long-term outcome data, so that our proposed brain injury scoring system has not yet been validated. The association between brain immaturity and late death in the SV cohort is interesting, but the number of patients is too small to make any definite conclusions. Finally, our final linear regression models account for only $9 \%$ to $30 \%$ of the factors associated with brain injury, meaning that we may not be measuring a number of other possible associated factors. These could include factors such as genotypic variation, inflammatory response, and any effect from hypoxic-ischemic preconditioning in these patients.
Many neonates having cardiac surgery have congenital and acquired conditions that contribute to neurologic disability and cannot be altered. In contrast, management strategies can be modified to limit perioperative insults. ${ }^{27}$ The important new finding of an association between MRI evidence of brain immaturity, with vulnerability to preand postoperative injury as well as late postoperative death, could have implications for management of these patients with regard to timing of delivery or surgery with bypass. Our finding that the immature brain in neonatal CHD is more vulnerable to MRI injury needs to be confirmed in other patient cohorts, and if validated could potentially be the basis for controlled trials of alternative approaches to improve early and late neurodevelopmental outcomes in neonates with CHD.

We thank Jhiyue Wang, $\mathrm{PhD}$, and Zili Chu, $\mathrm{PhD}$, for assistance with designing the MRI sequences and producing the postprocessing data for magnetic resonance spectroscopy. We also thank Tracie Jeffers, RRT, and Ivone Rodriguez, CRRT, for support with MRI studies; Marcie Garcia, RN, MS, Debora East, RN, BSN, Karol Arrington, RN, and Kathleen Carberry, RN, for assistance with patient enrollment, data collection, and database design and maintenance. 


\section{References}

1. Welke KF, Shen I, Ungerleider RM. Current assessment of mortality rates in congenital cardiac surgery. Ann Thorac Surg. 2006;82:164-71.

2. Wernovsky G, Shillingford AJ, Gaynor JW. Central nervous system outcomes in children with complex congenital heart disease. Curr Opin Cardiol. 2005;20: 94-9.

3. Creighton DE, Robertson CM, Sauve RS, Moddemann DM, Alton GY, NettelAguirre A, et al. Neurocognitive, functional, and health outcomes at 5 years of age for children after complex cardiac surgery at 6 weeks of age or younger. Pediatrics. 2007;120:e478-86.

4. Majnemer A, Limperopoulos C, Shevell M, Rosenblatt B, Rohlicek C, Tchervenkov C. Long-term neuromotor outcome at school entry of infants with congenital heart defects requiring open-heart surgery. J Pediatr. 2006;148:72-7.

5. Dent CL, Spaeth JP, Jones BV, Schwartz SM, Glauser TA, Hallinan B, et al. Brain magnetic resonance imaging abnormalities after the Norwood procedure using regional cerebral perfusion. J Thorac Cardiovasc Surg. 2006;131:190-7.

6. Mahle WT, Tavani F, Zimmerman RA, Nicolson SC, Galli KK, Gaynor JW, et al. An MRI study of neurological injury before and after congenital heart surgery. Circulation. 2002;106(suppl I): I-109-14.

7. Atallah J, Joffe AR, Robertson CM, Leonard N, Blakley PM, Nettel-Aguirre A, et al. Two-year general and neurodevelopmental outcome after neonatal complex cardiac surgery in patients with deletion 22q11.2: a comparative study. $J$ Thorac Cardiovasc Surg. 2007;134:772-9.

8. Wypij D, Newburger JW, Rappaport LA, duPlessis AJ, Jonas RA, Wernovsky G, et al. The effect of duration of deep hypothermic circulatory arrest in infant heart surgery on late neurodevelopment: the Boston Circulatory Arrest Trial. J Thorac Cardiovasc Surg. 2003;126:1397-403.

9. du Plessis AJ. Mechanisms of brain injury during infant cardiac surgery. Semin Pediatr Neurol. 1999;6:32-47.

10. Fraser CD Jr, Andropoulos DB. Principles of antegrade cerebral perfusion during arch reconstruction in newborns/infants. Semin Thorac Cardiovasc Surg Pediatr Card Surg Annu. 2008;61-8.

11. Andropoulos DB, Stayer SA, Diaz LK, Ramamoorthy C. Neurologic monitoring for congenital heart surgery. Anesth Analg. 2004;99:1365-75.

12. Jonas RA, Bellinger DC, Rappaport LA, Wernovsky G, Hickey PR, Farrell DM, et al. Relation of $\mathrm{pH}$ strategy and developmental outcome after hypothermic circulatory arrest. J Thorac Cardiovasc Surg. 1993;106:362-8.

13. Wypij D, Jonas RA, Bellinger DC, Del Nido PJ, Mayer JE Jr, Bacha EA, et al. The effect of hematocrit during hypothermic cardiopulmonary bypass in infant heart surgery: results from the combined Boston hematocrit trials. J Thorac Cardiovasc Surg. 2008;135:355-60.

\section{Appendix 1. Details of MRI Sequences}

MRI was performed using a 1.5-T scanner (Intera: Philips Medical Systems, Best, the Netherlands). Images obtained included standard T1- and T2-weighted images, as well as diffusion-weighted imaging, diffusion tensor imaging, and magnetic resonance spectroscopy. Technical details of the sequences are listed in the following table.

\section{Magnetic Resonance Spectroscopic Methods}

Proton spectra were be collected using 2-D chemical shift imaging (CSI) technique with the region of interest preselected by means of point-resolved spectroscopy through the plane of the basal ganglia. Four regions of interest included sample volumes in the left and right basal ganglia, and left and right thalami. Short echo time (relaxation time [TR]/echo time [TE] 1500/31 ms) were be used. The field of view for the 2-D CSI is $160 \times 160 \mathrm{~mm}$, with $16 \times 16$ phase encoding steps, yielding $10-\mathrm{mm}$ in-plane resolution.

In each subject, a single-voxel water reference spectrum was also obtained in the gray matter at the center of the
14. McQuillen PS, Barkovich AJ, Hamrick SE, Perez M, Ward P, Glidden DV, et al. Temporal and anatomic risk profile of brain injury with neonatal repair of congenital heart defects. Stroke. 2007;38:736-41.

15. Licht DJ, Shera DM, Clancy RR, Wernovsky G, Montenegro LM, Nicolson SC, et al. Brain maturation is delayed in infants with complex congenital heart defects. J Thorac Cardiovasc Surg. 2009;137:529-36.

16. Miller SP, McQuillen PS, Hamrick S, Xu D, Glidden DV, Charlton N, et al. Abnormal brain development in neonates with congenital heart disease. $N$ Engl J Med. 2007;357:1928-38.

17. Inder TE, Wells SJ, Mogridge NB, Spencer C, Volpe JJ. Defining the nature of the cerebral abnormalities in the premature infant: a qualitative magnetic resonance imaging study. J Pediatr. 2003;143:171-9.

18. Glass HC, Bonifacio SL, Chau V, Glidden D, Poskitt K, et al. Recurrent postnatal infections are associated with progressive white matter injury in premature infants. Pediatrics. 2008;122:299-305.

19. Ferriero DM. Neonatal brain injury. N Engl J Med. 2004;351:1985-95.

20. Partridge SC, Vigneron DB, Charlton NN, Berman JI, Henry RG, Mukherjee P, et al. Pyramidal tract maturation after brain injury in newborns with heart disease. Ann Neurol. 2006;59:640-51.

21. Childs AM, Ramenghi LA, Cornette L, Tanner SF, Arthur RJ, Martinez D, et al. Cerebral maturation in premature infants: quantitative assessment using MR imaging. AJNR Am J Neuroradiol. 2001;22:1577-82.

22. Back SA, Luo NL, Borenstein NS, Levine JM, Volpe JJ, Kinney HC. Late oligodendrocyte progenitors coincide with the developmental window of vulnerability for human perinatal white matter injury. J Neurosci. 2001;21: 1302-12.

23. Appachi E, Mossad E, Mee RB, Bokesch P. Perioperative serum interleukins in neonates with hypoplastic left heart syndrome and transposition of the great arteries. J Cardiothorac Vasc Anesth. 2007;21:184-90.

24. Galli KK, Zimmerman RA, Jarvik GP, Wernovsky G, Kuypers MK, Clancy RR, et al. Periventricular leukomalacia is common after neonatal cardiac surgery. J Thorac Cardiovasc Surg. 2004;127:692-704.

25. Ment LR, Bada HS, Barnes P, Grant PE, Hirtz D, Papile LA, et al. Practice parameter: neuroimaging of the neonate: report of the Quality Standards Subcommittee of the America Academy of Neurology and the Practice Committee of the Child Neurology Society. Neurology. 2002;58:1726-38.

26. McQuillen PS. Magnetic resonance imaging in congenital heart disease: what to do with what we see and don't see? Circulation. 2009;119:660-2.

27. Hsia TY, Gruber PJ. Factors influencing neurologic outcome after neonatal cardiopulmonary bypass: what we can and cannot control. Ann Thorac Surg. 2006;81:S2381-8
2-D CSI plane for signal intensity calibration (TR/TE/NSA $=5000 / 31 / 4)$. This is based on the assumption that the water content of the gray matter is relatively constant (approximately $78 \%$ ).

The first step in the data reduction for off-line magnetic resonance spectroscopy analysis is to import the localizer and 2-D CSI data for each subject into a software package (Spectro Tool; Philips Medical Systems). A separate program written Interactive Data Language (IDL, Research Systems, Denver, Colo) is used to convert the data in each region into a format for use in LCModel. Other corrections entered into the LCModel analysis included the relaxation effects of metabolites in the phantom and in normal brain tissue. Water scaling was done in the LCModel analysis by using the data from the water reference spectrum. The criterion for elevated lactate is the presence of elevated lactate doublet peak at 1.33 parts per million, defined as lactate:creatine ratio $>0.15$, when signal-tonoise ratio is acceptable. 


\begin{tabular}{|c|c|c|c|c|c|c|c|}
\hline Image type & $\begin{array}{c}\text { TR/TE } \\
(\mathrm{ms})\end{array}$ & $\begin{array}{c}\text { Flip } \\
\text { angle }\left(^{\circ}\right)\end{array}$ & $\begin{array}{l}\text { FOV } \\
(\mathbf{m m})\end{array}$ & $\begin{array}{c}\text { Section } \\
\text { thickness/ } \\
\text { gap (mm) }\end{array}$ & $\begin{array}{l}\text { Number } \\
\text { of slices }\end{array}$ & $\begin{array}{l}\text { Acquisition/ } \\
\text { reconstruction } \\
\text { matrix size }\end{array}$ & Other \\
\hline $\begin{array}{l}\text { 3-D FFE T1-weighted } \\
\text { sagittal }\end{array}$ & $20 / 4.1$ & 30 & 200 & $1.0 / 0.0$ & 100 & $224 / 256$ & \\
\hline $\begin{array}{l}\text { 3D TSE T2-weighted } \\
\text { sagittal }\end{array}$ & $3200 / 130$ & 90 & 200 & $1.0 / 0 / 0$ & 140 & $240 / 256$ & \\
\hline $\begin{array}{l}\text { SE PD/T2-weighted } \\
\quad \text { axial }\end{array}$ & $2500 / 18,120$ & 90 (refocus angle 140 ) & 200 & $5.0 / 1.0$ & 22 & $352 / 512$ & \\
\hline FFE axial & $610 / 23$ & 15 & 200 & $5.0 / 1.0$ & 20 & $256 / 256$ & \\
\hline $\begin{array}{r}\text { TSE T2-weighted } \\
\text { coronal FLAIR }\end{array}$ & $11,000 / 140$ (TI 2600) & 90 & 200 & $3.0 /-1.0$ & 53 & $256 / 256$ & \\
\hline $\begin{array}{r}15 \text { direction } \\
\text { axial DTI }\end{array}$ & $10,071 / 90$ & 90 & 256 & $2.7 / 0.0$ & 55 & $96 / 128$ & $\mathrm{~b}=0,860\left(\mathrm{c} / \mathrm{mm}^{2}\right)$ \\
\hline Axial DWI & $\begin{array}{c}10,000 / 81 \text { (IR delay } \\
2100)\end{array}$ & 90 & 200 & $6.0 / 1.0$ & 20 & $112 / 256$ & $\mathrm{~b}=0,1000\left(\mathrm{~s} / \mathrm{mm}^{2}\right)$ \\
\hline 3D SWI axial & $56 / 40$ & 20 & 256 & $2.0 / 0.0-$ & 32 & $512 / 512$ & \\
\hline
\end{tabular}

Appendix 2. Magnetic Resonance Imaging Abnormality Scoring System

\begin{tabular}{|c|c|c|c|c|c|c|c|}
\hline Category* & Subcategory & Score & $\begin{array}{c}\text { Outcome } \\
\text { significance } \\
\text { multiplier } \\
\end{array}$ & Definition & $\begin{array}{c}\text { Size (total mm, } \\
\text { largest diameter, } \\
\text { add all lesions) }\end{array}$ & Rule/example & $\begin{array}{l}\text { Magnetic } \\
\text { resonance } \\
\text { sequences } \\
\end{array}$ \\
\hline \multirow[t]{13}{*}{ Focal acquired } & WMI & 0 & 3 & None & 0 & $\uparrow \mathrm{T} 1, \pm \downarrow$ Dav & T1, Dav \\
\hline & WMI & 1 & 3 & Mild: $\leq 3,<2 \mathrm{~mm}$ & $1-5 \mathrm{~mm}$ & $\begin{array}{l}{\text { McQuillen et } \mathrm{al}^{12}} \text {; } \\
\text { Figure } 1, E-F\end{array}$ & \\
\hline & WMI & 2 & 3 & Moderate: $>3,>2 \mathrm{~mm}$ & $6-15 \mathrm{~mm}$ & & \\
\hline & WMI & 3 & 3 & $\begin{array}{l}\text { Severe: } 10 \% \text { white } \\
\text { matter }\end{array}$ & $>15 \mathrm{~mm}$ & & \\
\hline & $\begin{array}{l}\text { Infarction } \\
\text { (stroke- } \\
\text { ischemic) }\end{array}$ & 0 & 3 & None & 0 & $\begin{array}{c}\uparrow \mathrm{T} 2, \downarrow \text { Dav } \\
\text { (includes } \\
\text { watershed) }\end{array}$ & T2, Dav \\
\hline & Infarction & 1 & 3 & $\begin{array}{l}\text { Less than one-third of } \\
\text { vascular territory of } \\
\text { ACA, MCA, or } \\
\text { PCA in one } \\
\text { hemisphere }\end{array}$ & $1-5 \mathrm{~mm}$ & & \\
\hline & Infarction & 2 & 3 & $\begin{array}{l}\text { One-third to two- } \\
\text { thirds vasc territory }\end{array}$ & $6-15 \mathrm{~mm}$ & $\begin{array}{l}\text { McQuillen et } \mathrm{al}^{12} \text {; } \\
\text { Figure } 1, A-D\end{array}$ & \\
\hline & Infarction & 3 & 3 & $\begin{array}{l}>\text { Two-thirds vasc } \\
\text { territory }\end{array}$ & $>15 \mathrm{~mm}$ & & \\
\hline & $\begin{array}{c}\text { IP hemorrhage } \\
\text { (stroke- } \\
\text { hemorrhagic) }\end{array}$ & 0 & 3 & & 0 & $\uparrow \mathrm{T} 1, \downarrow \mathrm{T} 2, \downarrow \mathrm{SWI}$ & $\mathrm{T} 1, \mathrm{~T} 2, \mathrm{SWI}$ \\
\hline & IP hemorrhage & 1 & 3 & & $1-5 \mathrm{~mm}$ & & \\
\hline & IP hemorrhage & 2 & 3 & & $6-15 \mathrm{~mm}$ & & \\
\hline & IP hemorrhage & 3 & 3 & & $>15 \mathrm{~mm}$ & & \\
\hline & Punctate lesions & 0 & 2 & None & 0 & $\begin{array}{l}0-2 \mathrm{~mm} \text { discrete, } \\
\text { isolated lesions; } \\
\text { emboli from } \\
\text { platelet/fibrin } \\
\text { clot, air, other } \\
\text { particulate } \\
\text { material; } \\
\downarrow \mathrm{T} 2, \downarrow \mathrm{SWI}\end{array}$ & T2, SWI \\
\hline
\end{tabular}


Appendix 2. Continued

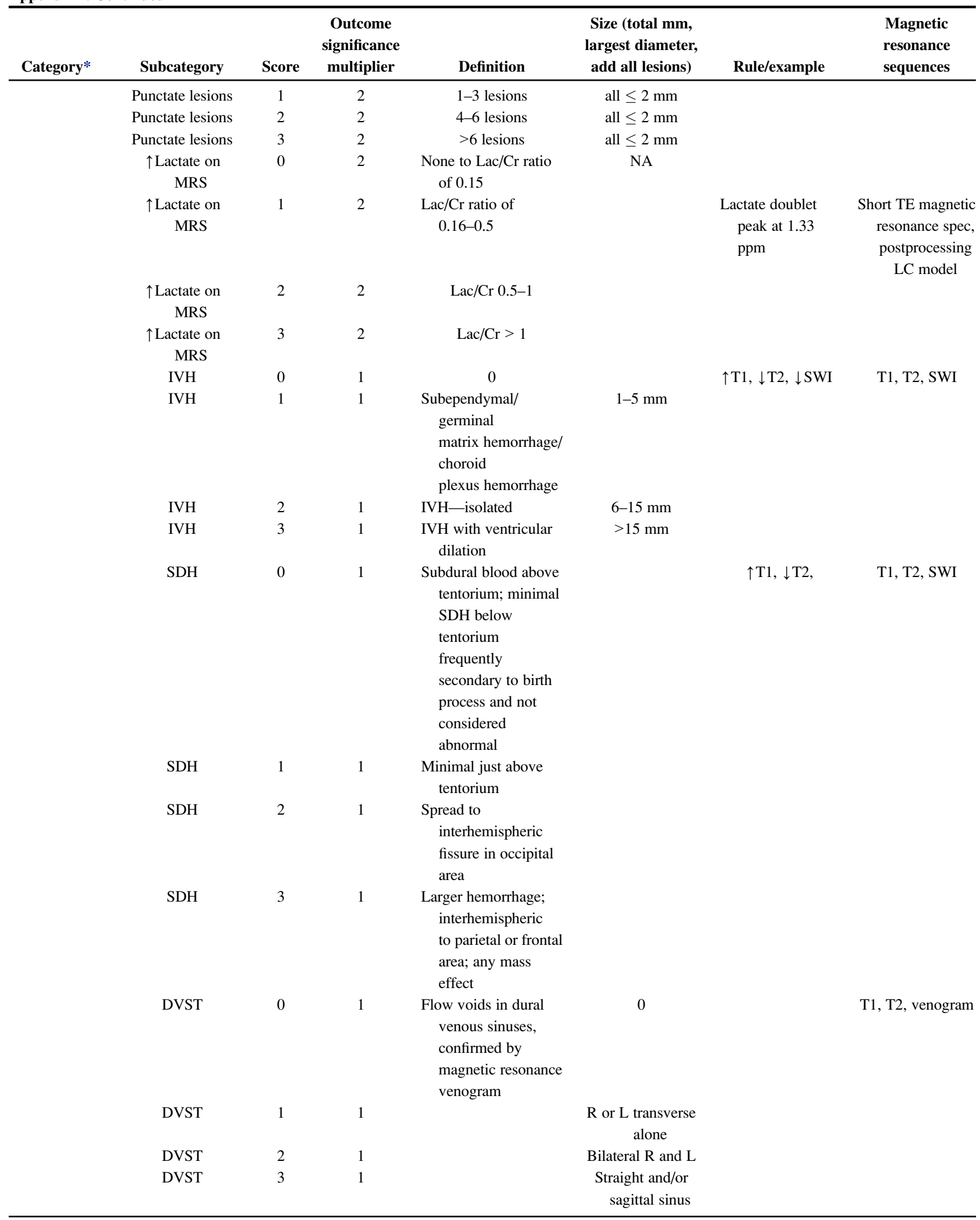


Appendix 2. Continued

\begin{tabular}{|c|c|c|c|c|c|c|c|}
\hline Category* & Subcategory & Score & $\begin{array}{c}\text { Outcome } \\
\text { significance } \\
\text { multiplier }\end{array}$ & Definition & $\begin{array}{l}\text { Size (total } \mathrm{mm} \text {, } \\
\text { largest diameter, } \\
\text { add all lesions) }\end{array}$ & Rule/example & $\begin{array}{l}\text { Magnetic } \\
\text { resonance } \\
\text { sequences }\end{array}$ \\
\hline \multirow[t]{4}{*}{$\begin{array}{l}\text { Congenital } \\
\text { malfor } \\
\text { mation }\end{array}$} & None & 0 & 1 & $\begin{array}{l}\text { Absent CC, Dandy- } \\
\text { Walker, venous } \\
\text { malformation, } \\
\text { cortical } \\
\text { malformation }\end{array}$ & $\begin{array}{c}\text { Semiobjective } \\
\text { severity }\end{array}$ & & $\mathrm{T} 1, \mathrm{~T} 2$ \\
\hline & & 1 & 1 & & & & \\
\hline & & 2 & 1 & & & & \\
\hline & & 3 & 1 & & & & \\
\hline $\begin{array}{l}\text { Develop- } \\
\text { mental }\end{array}$ & $\begin{array}{c}\text { See Total Maturity } \\
\text { Score }\end{array}$ & & & $\begin{array}{l}\text { Not included in total } \\
\text { injury score }\end{array}$ & & & $\mathrm{T} 1, \mathrm{~T} 2$ \\
\hline \multirow[t]{4}{*}{$\begin{array}{l}\text { Total injury } \\
\text { score }\end{array}$} & All categories & None & Total score 0 & $\begin{array}{l}\text { Multiply score in each } \\
\text { of } 9 \text { categories by } \\
\text { outcome } \\
\text { significance } \\
\text { multiplier }\end{array}$ & & & $\begin{array}{r}\text { T1, T2, DWI, Dav, } \\
\text { SWI, MR spec }\end{array}$ \\
\hline & & Mild & $\begin{array}{l}\text { Total score } \\
1-5\end{array}$ & $\begin{array}{l}\text { Sum all } 9 \text { subscores for } \\
\text { total score }\end{array}$ & & & \\
\hline & & & Moderate & Total score $6-10$ & $\begin{array}{c}\text { Range of scores: } \\
0-51\end{array}$ & & \\
\hline & & & Severe & Total score $>10$ & & & \\
\hline
\end{tabular}

$\overline{A C A}$, Anterior cerebral artery; $C C$, corpus callosum; $C r$, creatine; $D a v$, averaged diffusion coefficient maps; $D V S T$, dural sinovenous thrombosis; $D W I$, diffusion-weighted imaging; $I P$, intraparenchymal; $I V H$, intraventricular hemorrhage; $L a c$, lactate; $M C A$, middle cerebral artery; $M R S$, magnetic resonance spectroscopy; $P C A$, posterior cerebral artery; $S D H$, subdural hemorrhage; SWI, susceptibility-weighted imaging; WMI, white matter injury. *Definitions for WMI, IVH, and infarction (stroke) are from McQuillen et al ${ }^{12}$ and Partridge et al. ${ }^{20}$ 
Appendix 3. Magnetic Resonance Imaging Brain Development/Maturity Scoring System

\begin{tabular}{|c|c|c|}
\hline Category* & Designation/score & Definition \\
\hline \multirow[t]{7}{*}{ Myelination (M) } & M1 & Myelination evident in the brain stem, cerebellar peduncle, inferior colliculus, cerebellar vermis \\
\hline & M2 & M1 + subthalamic nucleus, globus pallidus, ventrolateral thalamus \\
\hline & M3 & $\mathrm{M} 2+$ caudal portion of the PLIC \\
\hline & M4 & $\mathrm{M} 3+$ complete PLIC \\
\hline & M5 & $\mathrm{M} 4+$ optic radiation \\
\hline & M6 & M5 + corona radiata \\
\hline & M7 & M6+ anterior limb of internal capsule \\
\hline \multirow[t]{6}{*}{ Cortical infolding $(\mathrm{C})$} & $\mathrm{C} 1$ & $\begin{array}{l}\text { Frontal and occipital cortex completely smooth, insula wide open; thin bright cortical rim on T1, generally } \\
\text { low-intensity WM on T1 }\end{array}$ \\
\hline & $\mathrm{C} 2$ & $\begin{array}{l}\text { Frontal cortex still very smooth, some sulci evident in occipital cortex; insula still wide with almost smooth } \\
\text { internal surface; WM low intensity on T1 }\end{array}$ \\
\hline & $\mathrm{C} 3$ & $\begin{array}{l}\text { Frontal and occipital cortex similar number of convolutions; frontal sulci still quite shallow; internal surface } \\
\text { of insula more convoluted; WM still somewhat low intensity on } \mathrm{T} 1\end{array}$ \\
\hline & $\mathrm{C} 4$ & $\begin{array}{l}\text { Frontal and occipital cortex folded and rich in sulci; frontal sulci obvious along interhemispheric fissure; } \\
\text { occipital WM separated into strands by deeper sulci; insula completely infolded; WM still } \\
\text { distinguishable from gray matter on T1 }\end{array}$ \\
\hline & C5 & $\begin{array}{l}\text { Frontal and occipital WM separated into strands by deeper sulci; insula completely infolded; WM still } \\
\text { distinguishable from gray matter on } \mathrm{T} 1\end{array}$ \\
\hline & C6 & As above but WM now isointense with gray matter on $\mathrm{T} 1$ \\
\hline \multirow[t]{4}{*}{ Germinal matrix (GM) } & GM1 & Matrix seen in posterior horn, CTN, and anterior horns of the lateral ventricles \\
\hline & GM2 & Matrix seen at CTN and anterior horns of the lateral ventricles \\
\hline & GM3 & Matrix seen in the anterior horns only \\
\hline & GM4 & No germinal matrix evident \\
\hline \multirow{4}{*}{$\begin{array}{l}\text { Bands of migrating glial } \\
\text { cells (B) }\end{array}$} & B1 & Broad band with additional narrower bands evident \\
\hline & B2 & Broad band alone \\
\hline & B3 & Narrow band alone \\
\hline & B4 & No bands seen \\
\hline
\end{tabular}

CTN, Caudothalamic notch; PLIC, posterior limb of the internal capsule; $W M$, white matter *From Childs. ${ }^{21}$

Appendix 4. MRI Data, Third MRI Scan at Age 3 to 6 Months

\begin{tabular}{|c|c|c|c|c|}
\hline Parameter & Single ventricle $(n=24)$ & Two ventricle $(n=21)$ & $P$ value & Total \\
\hline Age at third MRI (d) & $150 \pm 50$ & $189 \pm 71$ & $.04 *$ & $169 \pm 63$ \\
\hline MRI sedation complications (n) & 0 & 0 & $>.9$ & 0 \\
\hline WMI, n (\%) & $4(17)$ & $1(5)$ & .35 & $5(11)$ \\
\hline Infarct, n (\%) & $3(13)$ & $1(5)$ & .61 & $4(9)$ \\
\hline IP hemorrhage, $n(\%)$ & $1(4)$ & $1(5)$ & $>.9$ & $2(4)$ \\
\hline Punctate lesions, n (\%) & $3(13)$ & $4(19)$ & .69 & $7(16)$ \\
\hline MRS lactate, n (\%) & $1(4)$ & 0 & $>.9$ & $1(2)$ \\
\hline $\mathrm{SDH}, \mathrm{n}(\%)$ & $2(8)$ & 0 & .49 & $2(5)$ \\
\hline DVST, n $(\%)$ & $1(4)$ & 0 & $>.9$ & $1(2)$ \\
\hline IVH, n (\%) & $1(4)$ & 0 & $>.9$ & $1(2)$ \\
\hline Any finding, $\mathrm{n}(\%)$ & $8(33)$ & $5(24)$ & .71 & $13(29)$ \\
\hline New finding, $\mathrm{n}(\%)$ & $8(33)$ & $4(19)$ & .46 & $12(27)$ \\
\hline Complete resolution of findings, $\mathrm{n}(\%)$ & $5(21)$ & $12(57)$ & $.03 *$ & $17(38)$ \\
\hline Partial resolution of findings, $n(\%)$ & $6(25)$ & $3(14)$ & .47 & $9(20)$ \\
\hline Never abnormal findings & $5(21)$ & $2(10)$ & .42 & $7(16)$ \\
\hline MRI TMS & $17.5 \pm 2.0$ & $19.7 \pm 1.3$ & $<.001^{*}$ & $18.5 \pm 2.0$ \\
\hline Total MRI abnormality score & $2.3 \pm 3.1$ & $0.8 \pm 1.7$ & $.05^{*}$ & $1.6 \pm 2.7$ \\
\hline
\end{tabular}

$\overline{D V S T}$, Dural sinovenous thrombosis; $I P$, intraparenchymal; $I V H$, intraventricular hemorrhage; $M R I$, magnetic resonance imaging; $M R S$, magnetic resonance spectroscopy; $S D H$, subdural hemorrhage; TMS, Total Maturity Score; WMI, white matter injury. Data expressed as numbers of patients and percentages for MRI findings, and median days (25th-75th percentile interquartile range) for MRI days postoperatively. ${ }^{*} P<.05$ for between group differences. 